\title{
Sneathiella glossodoripedis sp. nov., a marine alphaproteobacterium isolated from the nudibranch Glossodoris cincta, and proposal of Sneathiellales ord. nov. and Sneathiellaceae fam. nov.
}

\author{
Midori Kurahashi, ${ }^{1}$ Yukiyo Fukunaga, ${ }^{1,2}$ Shigeaki Harayama ${ }^{2}$ \\ and Akira Yokota ${ }^{1}$ \\ ${ }^{1}$ Institute of Molecular and Cellular Biosciences, The University of Tokyo, Yayoi 1-1-1, Bunkyo-ku, \\ Tokyo 113-0032, Japan \\ ${ }^{2}$ NITE Biological Resource Center (NBRC), National Institute of Technology and Evaluation (NITE), \\ 2-5-8 Kazusa-kamatari, Kisarazu-shi, Chiba 292-0818, Japan
}

Correspondence

Midori Kurahashi

kuramido@iam.u-tokyo.ac.jp
The monophyletism of the class Alphaproteobacteria is widely supported by a number of phylogenetic analyses (Garrity et al., 2005), and the taxonomic name has been published in Validation List no. 107 (Garrity et al., 2006). Recent investigations, however, have indicated that the species belonging to the class Alphaproteobacteria are quite diverse in their phenotypic characteristics. Many species isolated from marine environments are classified in the classes Alphaproteobacteria and Gammaproteobacteria, and the numbers of bacteria of these classes are growing quickly. The objective of our study is to focus on the diversity of bacteria in gastrointestinal tracts and attached internal organs and on the epidermis of marine organisms (Kurahashi \& Yokota, 2002). We describe herein a novel bacterium that represents a distinct lineage and that forms a deep branch with Sneathiella chinensis in the Alphaproteobacteria. Sneathiella chinensis was reported as a novel genus and species in the class Alphaproteobacteria

The GenBank/EMBL/DDBJ accession number for the 16S rRNA gene sequence of strain MKT133' is AB289439.
(Jordan et al., 2007) and was considered to be a member of the order Rhizobiales. However, the present study indicates that Sneathiella chinensis with strain $\mathrm{MKT} 133^{\mathrm{T}}$ should be reclassified as members of a new order and family in the class Alphaproteobacteria.

Isolate MKT $133^{\mathrm{T}}$ was obtained from the foot epidermis of a nudibranch (Glossodoris cincta; Mollusca) collected in the sea off Aka island (Okinawa, Japan) from a depth of approximately $4 \mathrm{~m}$, using MG plates [per litre distilled water: $37.4 \mathrm{~g}$ marine broth 2216 (Becton Dickinson), $6.0 \mathrm{~g}$ gellan gum]. Standard methods were used for isolation and phenotypic characterization, as described previously (Kurahashi \& Yokota, 2004). Cultivation was performed on a marine agar 2216 (MA) plate at $30{ }^{\circ} \mathrm{C}$ for 1 week.

Colony morphology, size and colour were examined from cultures grown aerobically at $30{ }^{\circ} \mathrm{C}$ for 1 week on MA plates and R2AMN agar plates [per litre distilled water: R2A agar (Becton Dickinson), $18.2 \mathrm{~g} ; \mathrm{MgCl}_{2} \cdot 6 \mathrm{H}_{2} \mathrm{O}$, $10.0 \mathrm{~g} ; \mathrm{MgSO}_{4} \cdot 7 \mathrm{H}_{2} \mathrm{O}, 6.0 \mathrm{~g} ; \mathrm{NaCl}, 3.0 \mathrm{~g}$. Salt tolerance was tested in R2AM medium [per litre distilled water: R2A 
agar, $\left.18.2 \mathrm{~g} ; \mathrm{MgCl}_{2} \cdot 6 \mathrm{H}_{2} \mathrm{O}, 10.0 \mathrm{~g} ; \mathrm{MgSO}_{4} \cdot 7 \mathrm{H}_{2} \mathrm{O}, 6.0 \mathrm{~g}\right]$ supplemented with $0-8 \%(\mathrm{w} / \mathrm{v}) \mathrm{NaCl}$ after incubation for 1 week at $30{ }^{\circ} \mathrm{C}$. The Gram reaction was determined using the Becton Dickinson Gram stain kit, following the manufacturer's instructions. General cell morphology was studied using phase-contrast microscopy and transmission electron microscopy (TEM). Specimens for TEM were negatively stained with phosphotungstic acid. Biochemical tests were carried out using the API 20E and API ZYM microbial identification strips (bioMérieux). Results are given in the species description.

Strain MKT133 ${ }^{\mathrm{T}}$ was Gram-negative. Cells were rods, 0.2$0.3 \times 0.7-1.0 \mu \mathrm{m}$, slightly curved and motile in broth medium. One polar flagellum was present on negatively stained whole-cell preparations. Spore formation was not observed, and intracellular granules were detected in the cells. No growth was detected on R2A agar supplemented with only $\mathrm{NaCl}$, but was observed with the further addition of $\mathrm{MgCl}_{2} \cdot 6 \mathrm{H}_{2} \mathrm{O}$ and $\mathrm{MgSO}_{4} \cdot 7 \mathrm{H}_{2} \mathrm{O}$. Colonies on $\mathrm{MA}$ plates were colourless, circular, convex, smooth and less than $1.0 \mathrm{~mm}$ in diameter after incubation for 1 week at $30{ }^{\circ} \mathrm{C}$; compared with this, on R2AM medium supplemented with $3 \%(\mathrm{w} / \mathrm{v}) \mathrm{NaCl}$, colonies became slightly yellowish and were larger $(1.5-2.0 \mathrm{~mm})$. No growth was detected under anaerobic conditions, even with prolonged incubations of 30 days. The isolate grew at $17-45^{\circ} \mathrm{C}$, with optimum growth around $40{ }^{\circ} \mathrm{C}$. Strain $\mathrm{MKT}_{13} 3^{\mathrm{T}}$ could grow in the presence of up $4 \%(\mathrm{w} / \mathrm{v}) \mathrm{NaCl}$, and no growth was observed in medium containing no $\mathrm{NaCl}$, while growth of S. chinensis occurred without $\mathrm{NaCl}$ (Jordan et al., 2007). Phenotypic characteristics that differentiate strain MKT133 ${ }^{\mathrm{T}}$ from $S$. chinensis are summarized in Table 1 . These divergences demonstrate that strain MKT133 ${ }^{\mathrm{T}}$ represents a distinct species.

For the initial identification of whole-cell fatty acids, cells were grown for 1 week at $30{ }^{\circ} \mathrm{C}$ on MA. Cellular fatty acid

Table 1. Comparison of properties between strain MKT133 ${ }^{\top}$ and S. chinensis LMG $23452^{\top}$

Data for S. chinensis LMG $23452^{\mathrm{T}}$ were taken from Jordan et al. (2007) unless indicated. ND, No data available.

\begin{tabular}{|lcc|}
\hline Characteristic & Strain MKT133 $^{\text {T }}$ & $\begin{array}{c}\text { S. chinensis LMG } \\
\mathbf{2 3 4 5 2}^{\mathbf{T}}\end{array}$ \\
\hline Cell size $(\mu \mathrm{m})$ & $0.2-0.3 \times 0.7-1.0$ & $\mathrm{ND}$ \\
Growth without $\mathrm{NaCl}$ & - & + \\
Growth at $45{ }^{\circ} \mathrm{C}$ & + & - \\
Reduction of nitrite to $\mathrm{N}_{2}$ & - & $+^{*}$ \\
Production of acetoin & + & $-{ }^{*}$ \\
Arginine dihydrolase & + & $-{ }^{*}$ \\
Ornithine decarboxylase & + & $-+^{*}$ \\
Urease & - & 57.1 \\
G+C content (mol\%) & 56.9 & \\
\hline
\end{tabular}

${ }^{\star}$ Data from this study. methyl esters were prepared and analysed using gas chromatography according to the instructions of the Microbial Identification System (MIDI). Subsequently, to identify a mixed signal peak, separation of hydroxy and non-hydroxy fatty acid methyl esters was performed by TLC using $\mathrm{n}$-hexane/diethyl ether $(1: 1, \mathrm{v} / \mathrm{v})$. Each fraction was analysed again by the MIDI system. Respiratory quinones were extracted with chloroform/methanol $(2: 1$, $\mathrm{v} / \mathrm{v})$, fractionated by a spin column and identified by LCMS using an LCMS-QP8000 $\propto$ (Shimadzu). The G+C content of the DNA was determined by HPLC (Mesbah et al., 1989). DNA-DNA hybridization was performed to evaluate the genomic DNA relatedness between strain $\mathrm{MKT}_{133^{\mathrm{T}}}$ and S. chinensis LMG $23452^{\mathrm{T}}$. DNA-DNA hybridization experiments were carried out fluorometrically, using photobiotin-labelled DNA probes and microdilution wells as described by Ezaki et al. (1989). The temperature of renaturation was $48.3{ }^{\circ} \mathrm{C}$ for $18 \mathrm{~h}$.

The cellular fatty acid composition of $\mathrm{MKT}_{133^{\mathrm{T}}}$ was dominated by $\mathrm{C}_{18: 1} \omega 7 c(54.1 \%), \mathrm{C}_{16: 0}(13.6 \%), \mathrm{C}_{17: 1} \omega 6 c$ $(12.0 \%)$ and $\mathrm{C}_{14: 0} \quad 3-\mathrm{OH} \quad(4.2 \%)$ (Table 2). Strain MKT133 ${ }^{\mathrm{T}}$ and $S$. chinensis have very similar fatty acid profiles, considering the fact that fatty acids can be transformed biosynthetically (e.g. $\mathrm{C}_{18: 1} \omega 7 \mathrm{c} \rightarrow$ cyclo $\left.\mathrm{C}_{19: 0} \omega 8 c\right)$ by varying the culture conditions slightly. Many members of the Alphaproteobacteria are characterized by the dominant fatty acids $\mathrm{C}_{18: 1} \omega 7 c$ and $\mathrm{C}_{16: 0}$, indicating that the fatty acid data for MKT $133^{\mathrm{T}}$ and $S$. chinensis are consistent with a phylogenetic position within the class Alphaproteobacteria. However, the presence of large amounts of both $\mathrm{C}_{17: 1}$ and $\mathrm{C}_{14: 0} 3-\mathrm{OH}$ in these two strains is a distinct feature from other members of the Alphaproteobacteria. Detection of the quinone system Q-10 at a peak area ratio of approximately $93 \%$ is in agreement with the phylogenetic affiliation within the Alphaproteobacteria. The DNA G $+\mathrm{C}$ content of strain $\operatorname{MKT}_{133^{\mathrm{T}}}(56.9 \mathrm{~mol} \%)$ is almost the same as that of the reference strain S. chinensis CBMAI $737^{\mathrm{T}}(57.1 \mathrm{~mol} \%)$. The DNA-DNA relatedness between strain MKT133 ${ }^{\mathrm{T}}$ and $S$. chinensis LMG $23452^{\mathrm{T}}$ was about $22 \%$, clearly below the $70 \%$ threshold generally accepted for species delineation (Stackebrandt et al., 2002).

The 16S rRNA gene was amplified using universal primers as described previously (Kurahashi \& Yokota, 2004), and PCR products were sequenced directly in both directions. The sequences were analysed with the FASTA search system (Pearson \& Lipman, 1988) on the DDBJ website to find closely related bacterial 16S rRNA gene sequences. The sequence of the isolate was aligned with all GenBank entries. Alignment was performed using CLUSTAL W software (Thompson et al., 1994). Phylogenetic trees were inferred by neighbour-joining (Saitou \& Nei, 1987) with Kimura's two-parameter model (Kimura, 1980) and maximum-parsimony (Fitch, 1971) with a heuristic search. The topology of the phylogenetic tree was evaluated by using Felsenstein's bootstrap resampling method (Felsenstein, 1985) with 1000 replicates. 
Table 2. Cellular fatty acid compositions (\%) of strain MKT133 $^{\top}$ and S. chinensis LMG $23452^{\top}$

\begin{tabular}{|c|c|c|c|}
\hline \multirow[t]{2}{*}{ Fatty acid } & \multirow{2}{*}{$\begin{array}{c}\text { Strain } \\
\text { MKT133 }^{\mathrm{T}}\end{array}$} & \multicolumn{2}{|c|}{ S. chinensis LMG $23452^{\mathrm{T}}$} \\
\hline & & This study & $\begin{array}{c}\text { Jordan et al. } \\
\qquad(2007)\end{array}$ \\
\hline \multicolumn{4}{|l|}{ Hydroxy } \\
\hline $\mathrm{C}_{13: 0} 3-\mathrm{OH}$ & 0.5 & 0.5 & - \\
\hline $\mathrm{C}_{14: 0} 3-\mathrm{OH}$ & 4.2 & 6.6 & 2.7 \\
\hline \multicolumn{4}{|l|}{ Straight-chain } \\
\hline $\mathrm{C}_{9: 0}$ & 0.2 & 0.2 & - \\
\hline $\mathrm{C}_{10: 0}$ & 1.0 & 1.1 & - \\
\hline $\mathrm{C}_{12: 0}$ & 0.1 & 0.1 & - \\
\hline $\mathrm{C}_{14: 0}$ & 0.8 & 1.0 & 0.8 \\
\hline $\mathrm{C}_{15: 0}$ & 3.1 & - & 2.1 \\
\hline $\mathrm{C}_{16: 0}$ & 13.6 & 15.4 & 17.2 \\
\hline $\mathrm{C}_{17: 0}$ & 0.9 & 1.0 & 0.5 \\
\hline $\mathrm{C}_{18: 0}$ & 0.3 & 0.8 & - \\
\hline \multicolumn{4}{|l|}{ Unsaturated } \\
\hline $\mathrm{C}_{15: 1} \omega 8 c$ & 0.4 & 0.2 & 0.4 \\
\hline $\mathrm{C}_{15: 1} \omega 6 c$ & 0.1 & - & - \\
\hline $\mathrm{C}_{16: 1} \omega 11 c$ & - & - & 1.4 \\
\hline $\mathrm{C}_{16: 1} \omega 7 c$ & 2.8 & 2.7 & 7.0 \\
\hline $\mathrm{C}_{16: 1} \omega 5 c$ & 1.0 & 0.8 & 1.7 \\
\hline $\mathrm{C}_{17: 1} \omega 8 c$ & 1.5 & 0.9 & 0.7 \\
\hline $\mathrm{C}_{17: 1} \omega 6 c$ & 12.0 & 9.4 & 5.6 \\
\hline $\mathrm{C}_{18: 1} \omega 7 c$ & 54.1 & 56.2 & 46.2 \\
\hline $\mathrm{C}_{18: 1} \omega 5 c$ & 0.7 & 0.7 & 0.9 \\
\hline \multicolumn{4}{|l|}{ Branched } \\
\hline iso- $\mathrm{C}_{17: 1} \omega 9 c$ & 0.3 & 0.2 & - \\
\hline cyclo $\mathrm{C}_{19: 0} \omega 8 c$ & - & - & 9.8 \\
\hline \multicolumn{4}{|l|}{ Methyl } \\
\hline 11-Methyl & - & - & 0.3 \\
\hline $\mathrm{C}_{18: 1} \omega 7 c$ & & & \\
\hline Unknown & 0.9 & 1.8 & 1.1 \\
\hline Summed feature $2^{\star}$ & 0.8 & 0.3 & 1.7 \\
\hline Summed feature $4^{*}$ & 0.3 & - & - \\
\hline Summed feature $7^{*}$ & 0.4 & 0.4 & - \\
\hline
\end{tabular}

-, Not detected during analysis.

${ }^{*}$ Summed features: $2, \mathrm{C}_{12: 0}$ (aldehyde?); 4 , iso- $\mathrm{C}_{17: 1} \mathrm{I} /$ anteiso- $\mathrm{C}_{17: 1}$ $\mathrm{B} ; 7$, unknown equivalent chain-length $18.846 / \mathrm{C}_{19: 1} \omega 6 c$.

The FASTA search with the 16S rRNA gene sequence of MKT $133^{\mathrm{T}}$ showed that the newly determined sequence was related to those of the Alphaproteobacteria. The closest relatives of strain $\mathrm{MKT} 133^{\mathrm{T}}$ with validly published names were Sneathiella chinensis and Kordiimonas gwangyangensis, with 97.2 and $89.2 \%$ sequence similarity to the respective type strains. Type strains of other species belonging to the Alphaproteobacteria such as Mesorhizobium loti (89.2\%), Silicibacter lacuscaerulensis (88.5\%), Asticcacaulis excentricus $(88.2 \%)$, Parvularcula bermudensis (88.1\%), Sphingomonas paucimobilis $(88.8 \%)$, Rickettsia prowazekii $(86.6 \%)$ and Tistrella mobilis $(89.0 \%)$ showed less than $90 \% 16$ S rRNA gene sequence similarity. The phylogenetic position of the new isolate based on the 16S rRNA gene sequence is shown in Fig. 1. The phylogenetic tree suggested that the isolate formed a separate cluster with S. chinensis and two clones, as indicated by the $100 \%$ bootstrap value, thus creating a novel taxon. S. chinensis was considered to be a member of the order Rhizobiales by Jordan et al. (2007) but, in this study, the resultant phylogenetic tree revealed that $S$. chinensis forms a new phyletic lineage with strain $\mathrm{MKT} 133^{\mathrm{T}}$ distinct from all eight orders of the class Alphaproteobacteria. The class Alphaproteobacteria presently contains the orders Caulobacterales, Kordiimonadales, 'Parvularculales', Rhizobiales, Rhodobacterales, Rhodospirillales, Rickettsiales and Sphingomonadales, and segregates on a distinct, monophyletic 16S rRNA gene tree branch (Garrity et al., 2005; Kwon et al., 2005). Accordingly, it might be reasonable to suppose that the genus Sneathiella should be reclassified as a member of a new order.

On the basis of morphological and physiological characteristics, fatty acid profile, DNA G $+\mathrm{C}$ content and DNA-DNA relatedness, strain MKT133 ${ }^{\mathrm{T}}$ can be considered to be a member of the genus Sneathiella. However, there were some differences between strain MKT133 ${ }^{\mathrm{T}}$ and $S$. chinensis in their genetic and phenotypic characteristics. The phylogenetic distinctiveness was sufficient to categorize strain MKT $133^{\mathrm{T}}$ as a member of a species that is distinct from S. chinensis. The divergent phylogenetic relationships between the genus Sneathiella and established orders in the Alphaproteobacteria supported the creation of a new order and family within the class Alphaproteobacteria. On the basis of these results, strain MKT $133^{\mathrm{T}}$ is proposed as the type strain of a novel species of the genus Sneathiella, Sneathiella glossodoripedis sp. nov., in a new order and family.

\section{Description of Sneathiellales ord. nov.}

Sneathiellales (Snea.thi.el.la'les. N.L. fem. n. Sneathiella type genus of the order; -ales ending to denote an order; N.L. fem. n. Sneathiellales the order of Sneathiella).

Segregation of these organisms into a new order is justified by their distinct phyletic lineage based on the $16 \mathrm{~S}$ rRNA gene. The type genus is Sneathiella.

\section{Description of Sneathiellaceae fam. nov.}

Sneathiellaceae (Snea.thi.el.la'ceae. N.L. fem. n. Sneathiella type genus of the family; -aceae ending to denote an family; N.L. fem. n. Sneathiellaceae the family of Sneathiella).

Description is the same as that for the order. The type genus is Sneathiella.

\section{Description of Sneathiella glossodoripedis sp. nov.}

Sneathiella glossodoripedis [glos.so.do.ri.pe'dis. N.L. n. Glossodoris name of a zoological genus; L. gen. n. pedis of the foot; N.L. gen. n. Glossodoripedis of the foot of 


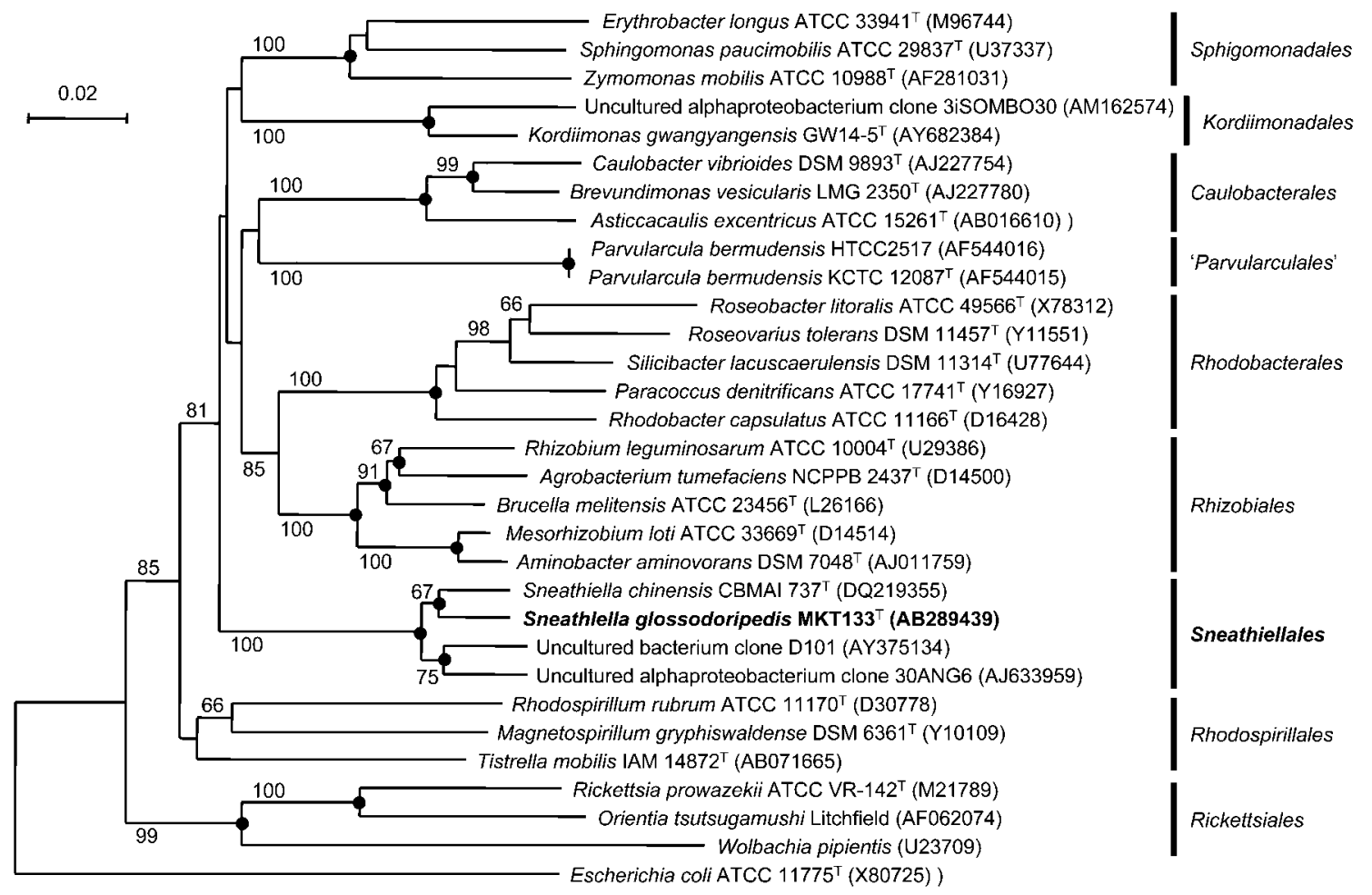

Fig. 1. Neighbour-joining tree showing the phylogenetic positions of strain $M K T 133^{\top}$ and representatives of the Alphaproteobacteria inferred from 16S rRNA gene sequence analyses. Percentages of 1000 bootstrap resamplings that support branching points above $65 \%$ confidence are indicated. Closed circles at nodes indicate recovered nodes with bootstrap values above $65 \%$ in a maximum-parsimony tree. Escherichia coli ATCC $11775^{\top}$ was used as an outgroup to define the root of the tree. Bar, 0.02 substitutions per nucleotide position.

Glossodoris (G. cincta), the source of isolation of the type strain].

Gram-negative. Cells are slightly curved rods, $0.2-$ $0.3 \times 0.7-1.0 \mu \mathrm{m}$, motile by one polar flagellum, nonspore-forming and have poly- $\beta$-hydroxybutyrate inclusions. Colonies on MA are colourless, circular, convex, smooth and less than $1.0 \mathrm{~mm}$ in diameter after incubation for 1 week at $30{ }^{\circ} \mathrm{C}$. Optimum growth occurs at $40{ }^{\circ} \mathrm{C}$, while no growth occurs at 10 or $50{ }^{\circ} \mathrm{C}$. Cultures grow aerobically, but not anaerobically. The ubiquinone system is Q-10 and the major cellular fatty acids are $\mathrm{C}_{18: 1} \omega 7 c$, $\mathrm{C}_{16: 0}, \mathrm{C}_{17: 1}$ and $\mathrm{C}_{14: 0}$ 3-OH. No growth occurs without $\mathrm{NaCl}$. The DNA $\mathrm{G}+\mathrm{C}$ content of the type strain is $56.9 \mathrm{~mol} \%$. The type strain is positive for catalase, oxidase, arginine dihydrolase, ornithine decarboxylase, tryptophan deaminase, production of acetoin, utilization of citrate and reduction of nitrate to nitrite, but negative for urease, gelatinase, production of $\mathrm{H}_{2} \mathrm{~S}$ and indole, reduction of nitrite to $\mathrm{N}_{2}$ and assimilation of D-glucose, D-mannose, inositol, sorbitol, rhamnose, sucrose, melibiose, amygdalin and arabinose. In assays with the API ZYM system, alkaline phosphatase, esterase (C4) (weak), esterase lipase (C8) (weak), leucine arylamidase, trypsin (weak), acid phosphatase, naphthol-AS-BI-phosphohydrolase, $\alpha$-glucosidase (weak) and $N$-acetyl- $\beta$-glucosaminidase are detected, but lipase (C4), valine arylamidase, cystine arylamidase, $\alpha$ chymotrypsin, $\alpha$-galactosidase, $\beta$-galactosidase, $\beta$-glucuronidase, $\beta$-glucosidase, $\alpha$-mannosidase and $\alpha$-fucosidase are not detected.

The type strain is MKT133 ${ }^{\mathrm{T}}$ (=IAM $15419^{\mathrm{T}}=\mathrm{KCTC}$ $\left.12842^{\mathrm{T}}\right)$, which was isolated from the nudibranch Glossodoris cincta off Aka island, Okinawa, Japan.

\section{Acknowledgements}

We thank Dr Jean P. Euzéby (Ecole Nationale Vétérinaire, Toulouse, France) for his help in the latinization of the new species name. This work was supported in part by a Grant-in-Aid for Scientific Research (no. 17310135) from the Ministry of Education, Culture, Sports, Science, and Technology of Japan. Y.F. and S. H. thank the New Energy and Industrial Technology Development Organization (NEDO) for financial support.

\section{References}

Ezaki, T., Hashimoto, Y. \& Yabuuchi, E. (1989). Fluorometric deoxyribonucleic acid-deoxyribonucleic acid hybridization in microdilution wells as an alternative to membrane filter hybridization in 
which radioisotopes are used to determine genetic relatedness among bacterial strains. Int J Syst Bacteriol 39, 224-229.

Felsenstein, J. (1985). Confidence limits on phylogenies: an approach using the bootstrap. Evolution 39, 783-791.

Fitch, W. M. (1971). Toward defining the course of evolution: minimum change for a specific tree topology. Syst Zool 20, 406-416.

Garrity, G. M., Bell, J. A. \& Lilburn, T. (2005). Class I. Alphaproteobacteria class. nov. In Bergey's Manual of Systematic Bacteriology, 2nd edn, vol. 2, part C, p. 1. Edited by D. J. Brenner, N. R. Krieg, J. T. Staley \& G. M. Garrity. New York: Springer.

Garrity, G. M., Bell, J. A. \& Lilburn, T. (2006). Alphaproteobacteria class. nov. In List of New Names and New Combinations Previously Effectively, but not Validly, Published, List no. 107. Int J Syst Evol Microbiol 56, 1-6.

Jordan, E. M., Thompson, F. L., Zhang, X.-H., Li, Y., Vancanneyt, M., Kroppenstedt, R. M., Priest, F. G. \& Austin, B. (2007). Sneathiella chinensis gen. nov., sp. nov., a novel marine alphaproteobacterium isolated from coastal sediment in Qingdao, China. Int J Syst Evol Microbiol 57, 114-121.

Kimura, M. (1980). A simple method for estimating evolutionary rates of base substitutions through comparative studies of nucleotide sequences. J Mol Evol 16, 111-120.

Kurahashi, M. \& Yokota, A. (2002). A preliminary report of phylogenetic diversity of bacterial strains isolated from marine creatures. J Gen Appl Microbiol 48, 251-259.
Kurahashi, M. \& Yokota, A. (2004). Agarivorans albus gen. nov., sp. nov., a $\gamma$-proteobacterium isolated from marine animals. Int $J$ Syst Evol Microbiol 54, 693-697.

Kwon, K. K., Lee, H. S., Yang, S. H. \& Kim, S. J. (2005). Kordiimonas gwangyangensis gen. nov., sp. nov., a marine bacterium isolated from marine sediments that forms a distinct phyletic lineage (Kordiimonadales ord. nov.) in the 'Alphaproteobacteria'. Int J Syst Evol Microbiol 55, 2033-2037.

Mesbah, M., Premachandran, U. \& Whitman, W. B. (1989). Precise measurement of the $\mathrm{G}+\mathrm{C}$ content of deoxyribonucleic acid by highperformance liquid chromatography. Int J Syst Bacteriol 39, 159-167.

Pearson, W. R. \& Lipman, D. J. (1988). Improved tools for biological sequence comparison. Proc Natl Acad Sci U S A 85, 2444-2448.

Saitou, N. \& Nei, M. (1987). The neighbor-joining method: a new method for reconstructing phylogenetic trees. Mol Biol Evol 4, 406-425.

Stackebrandt, E., Frederiksen, W., Garrity, G. M., Grimont, P. A. D., Kämpfer, P., Maiden, M. C. J., Nesme, X., Rosselló-Mora, R., Swings, J. \& other authors (2002). Report of the ad hoc committee for the reevaluation of the species definition in bacteriology. Int J Syst Evol Microbiol 52, 1043-1047.

Thompson, J. D., Higgins, D. G. \& Gibson, T. J. (1994). CLUSTAL W: improving the sensitivity of progressive multiple sequence alignment through sequence weighting, position-specific gap penalties and weight matrix choice. Nucleic Acids Res 22, 4673-4680. 